\title{
Effect of Cell Genome Editing on the Outcome of Neurotransplantation in Experimental Parkinsonism
}

\author{
DOI: $10.17691 / \mathrm{stm} 2017.9 .4 .01$
}

Received August 2, 2017

A.V. Stavrovskaya, PhD, Head of the Laboratory of Experimental Pathology of the Nervous System';

E.V. Novosadova, PhD, Researcher, Laboratory of Molecular Genetics of Somatic Cells²;

A.S. Olshansky, PhD, Senior Researcher, Laboratory of Experimental Pathology of the Nervous System 1 ;

N.G. Yamshchikova, PhD, Leading Researcher, Laboratory of Experimental Pathology of the Nervous System';

A.S. Gushchina, Researcher, Laboratory of Experimental Pathology of the Nervous System';

E.L. Arsenyeva, PhD, Researcher, Laboratory of Molecular Genetics of Somatic Cells;

I.A. Grivennikov, DSc, Professor, Head of the Laboratory of Molecular Genetics of Somatic Cells';

S.N. Illarioshkin, MD, DSc, Professor, Corresponding Member of the Russian Academy of Sciences, Deputy Director for Science, Head of the Department for Brain Research ${ }^{1}$

${ }^{1}$ Research Center of Neurology, 80 Volokolamskoye Shosse, Moscow, 125367, Russian Federation;

${ }^{2}$ Institute of Molecular Genetics of the Russian Academy of Sciences, 2 Academician Kurchatov Square,

Moscow, 123182, Russian Federation

The aim of the study was to evaluate the effect of genome editing on the outcome of experimental transplantation of neuronal precursors obtained from a patient with the hereditary form of Parkinson's disease.

Materials and Methods. Parkinsonian syndrome was modeled in Wistar rats $(n=24)$ by unilateral administration (into the substantia nigra) of the neurotoxin 6-hydroxydopamine, that selectively destroy dopaminergic neurons. The neural progenitors were differentiated from induced pluripotent stem cells (iPSCs) derived from a patient with the PARK8 form of Parkinson's disease carrying the G2019S mutation in the LRRK2 gene. In two series of experiments, the cells containing the mutated gene and the isogenic "normalized" cells (that underwent genome editing using the artificial endonuclease system CRISP/Cas9) were used for neurotransplantation. The neuronal precursors were transplanted via a unilateral injection into the brain striatum of rats. We then monitored changes in the behavior of experimental animals using the open field test and the passive avoidance response (PAR) test. The data was processed using the Statistica 7.0 software with the single-factor analysis of variance (ANOVA).

Results. The administration of neuronal precursors into the rat brain striatum led to a gradual restoration of motor activity in the experimental animals of both groups, i.e., those transplanted with either mutant or "normalized" cells. In the PAR test, the rats transplanted with mutant cells failed to reproduce the conditioned responses, whereas the rats transplanted with "normalized" cells were able to reproduce the avoidance responses in the way similar to that in intact rats. The latent period before entering the dark box differed between the two groups of animals with a high degree of statistical significance.

Conclusion. The study confirms the possibility of correcting motor and cognitive impairments in experimental parkinsonian rats by replenishing the pool of dopaminergic neurons with neuronal precursors produced from iPSCs derived from somatic cells (fibroblasts). Using genome editing to correct the causal mutation in iPSCs before transplantation significantly improves the treatment results. This study, therefore, provides the rationale for further development of this promising technique and its eventual use in patients with genetically determined forms of Parkinson's disease.

Key words: parkinsonism; 6-hydroxydopamine; induced pluripotent stem cells; genome editing; neurotransplantation.

Parkinson's disease (PD) is one of the most common neurodegenerative disorders; genetic factors have been implicated in the development of PD [1]. The major clinical manifestations of PD include movement disorders (bradykinesia, muscle rigidity, rest tremor) associated with dysfunction of pigmented neurons

For contacts: Sergey N. Illarioshkin, e-mail: snillario@gmail.com 
located in the substantia nigra of the midbrain. As these neurons normally produce dopamine, their failure in PD leads to degeneration of the nigrostriatal dopaminergic pathway [2]. PD is an age-related disease, occurring in $1-2 \%$ of individuals over 70 years old [3]. Because of the ongoing increase in the elderly population around the world, PD becomes a factor of social significance.

The existing therapies of PD are mainly symptomatic and cannot prevent the progression of the neurodegenerative process. Among the novel therapeutic approaches, there is a notable trend to treat PD by replenishing dopamine in the CNS using exogenous dopamine-producing cells transplanted into the affected brain tissue [4-6]. Neurotransplantation in human PD using fetal midbrain tissues and neurons derived from embryonic stem cells demonstrated that transplanted cells could re-innervate the striatum, restore dopaminergic neurotransmission, and in some cases improve motor function; however these effects were poorly reproducible $[7,8]$. To date, transplantation into the striatum of fully-functioning dopaminergic neurons, differentiated from induced pluripotent stem cells (iPSCs), is considered to be a real and most promising approach to the treatment of PD [9-12]. The iPSCs can be obtained from reprogrammed somatic tissues (fibroblasts) of PD patients themselves [13], which rule out ethical problems and ensures the genetic identity of the transplanted cells and the recipient tissues.

We have previously shown $[14,15]$ that iPSCs can be used to treat experimental parkinsonism caused by injecting the selective dopaminergic toxin 6-hydroxydopamine (6-OHDA) into the substantia nigra of the rat brain. Stereotaxic transplantation of human dopaminergic neurons (differentiated from human iPSCs) into the striatum of rats improved their motor functions and reduced symptoms of parkinsonism. It remains unclear, however, if the novel method of neurotransplantation will be effective in the cases of PD caused by genetic factors, i.e. mutations in parkinsonian genes, which are present in $5-10 \%$ of PD patients $[1,3]$. The answer to this question is important for the prospects of neurotransplantation in hereditary forms of PD.

The aim of the study was to evaluate the outcome of an experimental transplantation procedure involving mutant and "normalized" isogenic neuronal precursors obtained from induced pluripotent stem cells of a patient with the autosomal dominant form of Parkinson's disease (point mutation in the LRRK2 gene) and subjected to genome editing with the artificial endonuclease system CRISP/Cas9.

\section{Materials and Methods}

Parkinson's disease was modeled in 3-4-month old Wistar rats. The rats were kept in the Institute's animal house with free access to food and water under alternating illumination of $12 \mathrm{~h}$ of light/12 $\mathrm{h}$ of darkness. The animals were kept and experiments were carried out in accordance with the Guide for the Care and Use of Laboratory Animals. The work with the animals was performed according to the ethical principles of the European Convention for the Protection of Vertebrate Animals used for Experimental and Other Scientific Purposes (adopted in Strasbourg on 18.03.1986 and confirmed in Strasbourg on 15.06.2006) and approved by the Ethics Committee of the Research Center for Neurology.

To simulate the parkinsonian syndrome, dopaminergic neurons of the substantia nigra of the rat brains were destroyed by injecting the neurotoxin 6-OHDA (Sigma, USA). In total, 24 rats were used in this experimentation. To perform stereotactic surgery, anesthetized animals were placed on the frame of a double laboratory stereotaxic manipulator (Stoelting Co., USA). During the operation, $6-\mathrm{OHDA}(10.0 \mu \mathrm{g}$ in $2 \mu \mathrm{l}$ of $0.05 \%$ solution of ascorbic acid) was injected at a rate of $0.4 \mu \mathrm{l} / \mathrm{min}$ to the right part of the brain. The stereotaxic coordinates were taken from the rat brain atlas [16]: $A P=-4.8$, $\mathrm{V}=1.9, \mathrm{~L}=8.0$. For anesthesia, Zoletil 100 at $3 \mathrm{mg} / 100 \mathrm{~g}$ and Xylanit at $3 \mathrm{mg} / \mathrm{kg}$ intramuscularly were used. For premedication, Atropine at $0.04 \mathrm{mg} / \mathrm{kg}$ was injected subcutaneously 10-15 min before the administration of Xylanit. Normal saline was administered into the substantia nigra on the left.

After the manifestations of parkinsonian syndrome appeared, the animals were divided into two groups of 12 rats in each for the subsequent neurotransplantation of two types of neuronal progenitors (see below). Transplantation was performed in the area of caudal nuclei under the guidance of the rat brain atlas [16] $(A P=1.5, V=2.5, L=4.8)$. The animals were anesthetized using the same procedure as described above.

Cell transplantation was performed unilaterally, on the same side where the 6-OHDA had been previously injected. A suspension of differentiated cells in $10 \mu \mathrm{l}$ of saline was injected into the caudal nuclei. The suspension placed in a $25-\mu \mathrm{L}$ Hamilton's micro-syringe was administered with a constant rate of $1.0 \mu \mathrm{l} / \mathrm{min}$ for $10 \mathrm{~min}$. After the injection, the micro-syringe was left in place for additional $2 \mathrm{~min}$, and then slowly removed within $1 \mathrm{~min}$. Ten $\mu \mathrm{l}$ of saline was injected into the caudal nuclei on the left. One day before surgery and every next day after it, the animals received cyclosporine at $5 \mathrm{mg} / \mathrm{kg}$.

The following iPSC lines (developed previously) were used in the work [17]:

cells from a patient with the autosomal dominant form of PD (the PARK8 form, mutation G2019S in the LRRK2 gene); those were defined as IPSPDL2.15L (hereinafter referred to as "sick" cells);

cells from the same patient after genome editing, during which the mutation was repaired to restore the normal nucleotide sequence of the LRRK2 gene - this was the IPSPDL2.15 wt line (hereinafter - the "edited" cells).

iPSC cultures. Cells were cultured in Petri dishes 35 and $60 \mathrm{~mm}$ (Greiner Bio-One, Austria) on a Matrigel substrate (BD Biosciences, USA) in $\mathrm{mTeSR}$ medium 
(STEMCELL Technologies, Canada). The medium was changed once a day. For a passage, the cells were removed from the substrate using the enzyme dispase at $1 \mathrm{mg} / \mathrm{ml}$ (Gibco, USA) co-incubated with the cells for 7-10 min in a $\mathrm{CO}_{2}$ incubator at $37^{\circ} \mathrm{C}$. After this, the cells were washed 5 times using DMEM medium (PanEco, Russia). Then the cell colonies were mechanically removed with the wide end of a $200 \mu$ l plastic tip, transferred to $1 \mathrm{ml}$ of $\mathrm{mTeSR}$ medium, and plated into a new Matrigel-coated Petri dish containing $1 \mathrm{ml}$ of $\mathrm{mTeSR}$ medium. Cell passages (1:2 or $1: 3$ ) were performed every 5-7 days.

Differentiation of iPSCs into neuronal progenitors. The iPSCs were cultured in mTeSR medium to $80 \%$ confluency; the medium was then replaced with the "neuronal" medium composed of DMEM/F12 medium (Gibco, USA); the $2 \%$ serum substitute (Gibco, USA); $1 \mathrm{mM}$ non-essential amino acids (PanEco, Russia); $2 \mathrm{mM}$ L-glutamine (ICN Biomedical, USA); penicillinstreptomycin (50 U/ml, $50 \mu \mathrm{g} / \mathrm{ml}$; PanEco, Russia); the additive $1 \%$ N2 (Life Technologies, USA); the SB431542 inhibitor, $10 \mu \mathrm{M}$ (Stemgent, USA); the protein Noggin, $80 \mathrm{ng}$ (Peprotech, USA). The medium was changed daily for 7-10 days. The neuronal rosettes and ridges formed with time were mechanically separated and transferred to a 24-well plate with ultra-low attachment (Costar, USA). Neuro-spheres subsequently formed were continuously cultured for another 5-7 days.

Neuro-spheres were collected into centrifuge tubes, and then dissociated with $0.05 \%$ trypsin so to produce a single cell suspension. They were then plated again in Matrigel-coated Petri dishes into the "neuronal" medium composed of DMEM/F12 medium; the $2 \%$ serum substitute; $1 \mathrm{mM}$ of non-essential amino acids; $2 \mathrm{mM}$ L-glutamine; penicillin-streptomycin $(50 \mathrm{U} / \mathrm{ml}$, $50 \mu \mathrm{g} / \mathrm{ml}$ ); the additive 1\% N2; 1\% B27 (Gibco, USA); the SB431542 inhibitor, $10 \mu \mathrm{M}$; the protein Noggin, $80 \mathrm{ng}$, supplemented with $5 \mu \mathrm{M}$ ROCK inhibitor (Stemolecule Y27632; Stemgent, USA). Upon forming a dense monolayer, the neuronal precursors were passaged at $1: 4$.

Preparing neuronal precursors for transplantation. The neuronal precursors of the $2^{\text {nd }}-4^{\text {th }}$ passage were incubated in the neuronal medium at a density of $\sim 200,000$ cells $/ \mathrm{cm}^{2}$ in Matrigel-coated Petri dishes.

The next day, the medium was replaced with the differentiation medium: DMEM/F12 medium; $2 \%$ serum substitute; $1 \%$ additive $\mathrm{B} 27 ; 2 \mathrm{mM}$ glutamine; $1 \%$ mixture of amino acids (PanEco, Russia); penicillin-streptomycin (50 U/ml, $50 \mu \mathrm{g} / \mathrm{ml}$ ); protein Shh, $100 \mathrm{ng} / \mathrm{ml}$ (PeproTech, USA); FGF8, $100 \mathrm{ng} / \mathrm{ml}$ (PeproTech, USA) and $10 \mu \mathrm{M}$ purmorphamine (Stemgent, USA).

The cells were cultured for 6-8 days with that medium, which was changed every other day. On the day of replanting, the cells were removed with trypsin $(0.05 \%)$, gently pipetted, and counted in a Goryaev's chamber; the calculated amount of suspension was centrifuged at $350 \mathrm{~g}$ for $5 \mathrm{~min}$. The supernatant was removed and the cells pipetted with the differentiation medium added with $5 \mu \mathrm{M}$ of the ROCK inhibitor. 500,000 cells (for IPSPDL2.15L) or 250,000 cells (for IPSPDL2.15 wt) per one rat were used for transplantation. The cell suspension was aliquoted (500 or 200 thousand cells) in $1 \mathrm{ml}$ of the medium into Eppendorf tubes and placed in a water bath at $37^{\circ} \mathrm{C}$. Just prior to use, the Eppendorf tube with the cells was taken from the water bath and microfuged at 2,000 rpm for $5 \mathrm{~min}$; the supernatant was carefully removed and $10 \mu \mathrm{l}$ of sterile $0.9 \% \mathrm{NaCl}$ was added. The cell suspension was gently pipetted and collected into a micro-syringe for subsequent injection.

Physiological tests. The motor functions of the rats were assessed using the open field test: the number of squares crossed for 3 min was counted. The cognitive impairment and the emotional status of experimental rats were evaluated using the passive avoidance responses (PAR) test. This test allows assessing both cognitive impairment and emotional changes in rats with various experimental disorders, and specifically with parkinsonian syndrome [18-20]. The development of reproducible passive defensive responses in rats was evaluated by the duration of the latent period before the animal traveled from a bright day-light box to a dark box where (on the previous day) this rat was painfully and unavoidably given an electric shock (a constant current of $0.2 \mathrm{~mA}, 3 \mathrm{~s}$ ). The PAR tests were carried out on days $1,3,7$ and 14 after the electrical aversive stimulus was given. The tests were controlled by the ShutAvoid 1.8.03 software and performed using a PanLab/Harvard Apparatus machine (Spain).

The data was processed in Statistica 7.0 using the single-factor analysis of variance (ANOVA). The differences were considered statistically significant at $p<0.05$.

At the end of the physiological experiments, the animals were euthanized with chloroform, and then decapitated; the brain was extracted for subsequent immunohistochemical studies.

Results. The development of parkinsonian syndrome in experimental animals was observed within 4 weeks after the injection of neurotoxin into the substantia nigra of the brain. More details on the neuronal impairment in this PD model are given in our earlier publication [15]. Neurotransplantation of differentiated iPSCs of various lines was performed at the time when the motor disabilities in the affected rats clearly manifested but no akinesia occurred.

Of particular interest was to compare the outcomes of neurotransplantation of isogenic iPSCs of two species mutant and "wild" (restored after genome editing); no such data was available in the literature. To that end, the motor and cognitive functions of experimental animals were monitored before and after the transplantation procedures.

Two weeks after the surgery, motor activity of the animals was tested in the open field setting. Earlier, we showed [14] that the administration of differentiated 
iPSCs resulted in a gradual recovery of the motor activity in rats with experimental parkinsonism. This result was reproduced in the present study: in both groups of animals, the motor activity improved upon neurotransplantation with no significant differences between the groups (Figure 1).

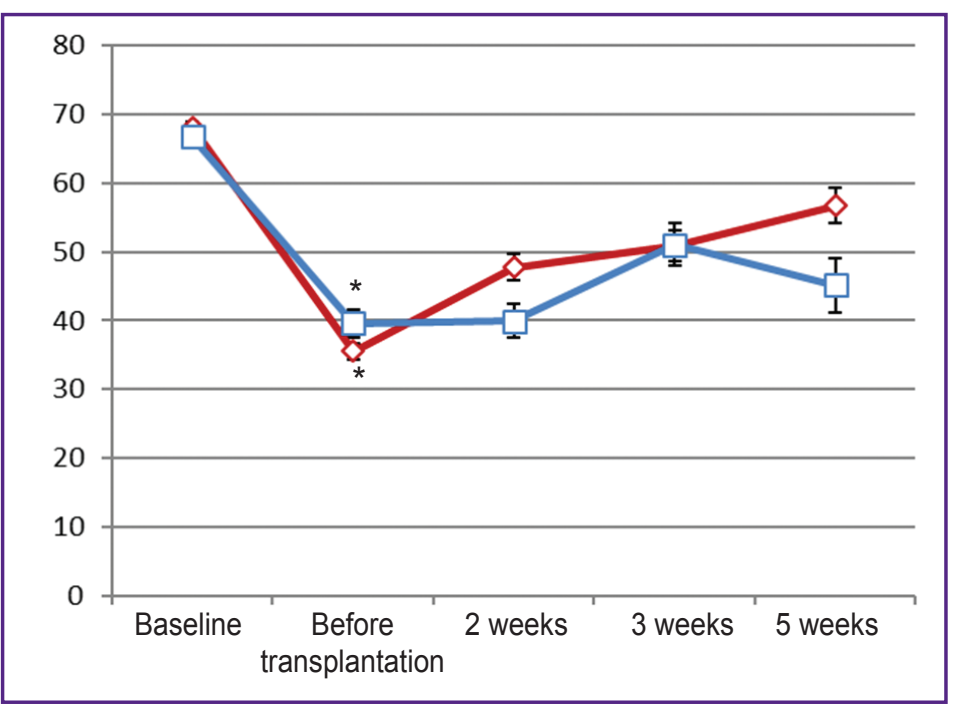

Figure 1. Restoration of motor activity of experimental rats in the open field:

The ordinate - the number of squares crossed by the animal; the abscissa - the time point of testing. Red line - rats transplanted with cells from a PD patient ("sick" cells); blue line — rats transplanted with "edited" cells from the same PD patient. * When compared with the motor activity in rats before neurotransplantation, the value is significantly different; $p \leqslant 0.05$

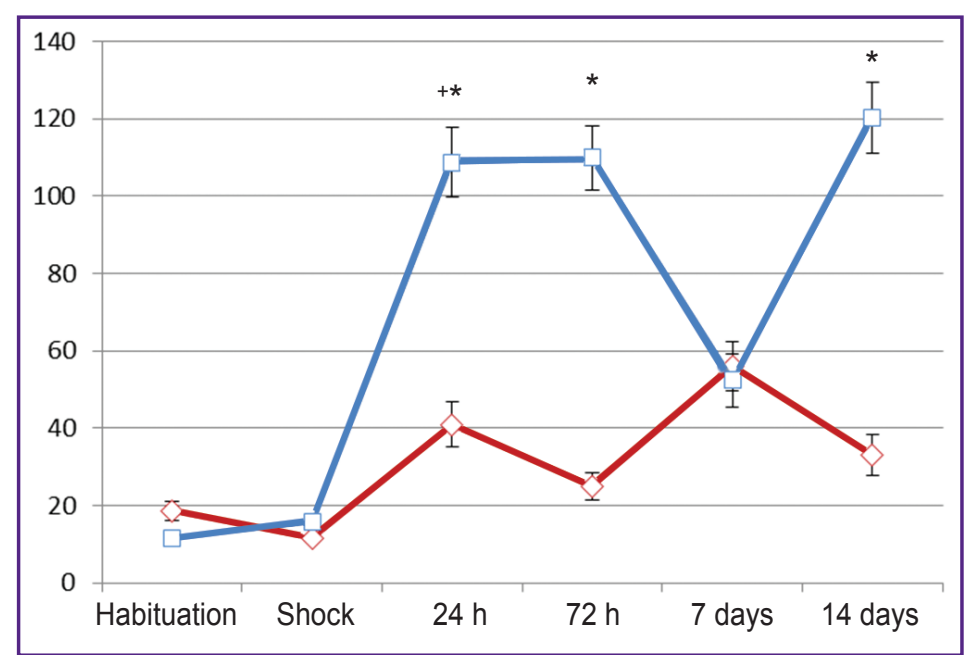

Figure 2. Duration of the latency period preceding the passage of rats into the dark chamber:

The ordinate - latency duration (s); the abscissa - the time point of testing. Red line - rats transplanted with cells from a PD patient ("sick" cells); blue line — rats transplanted with "edited" cells from the same PD patient. + When compared with the value on the day of electric shock, the value is significantly different; $p \leqslant 0.05$. ${ }^{*}$ When compared with the "sick" cells, the value is significantly different; $p \leqslant 0.05$
After achieving a stable improvement in locomotion (i.e., 4 weeks after the neurotransplantation), reproducible passive avoidance responses in rats were tested (Figure 2). Animals with transplanted mutant ("sick") cells demonstrated poor ability to reproduce the conditioned responses. All these animals passed into the dark compartment after a short latent period, which remained almost unchanged in subsequent tests. Moreover, within the entire period of testing, there was no significant correlation between the latency duration and the time passed after the electrical shock.

In rats with transplanted "normalized" cells (i.e., neuronal precursors with restored genotype), the PAR results were close to the normal pattern typical for intact rats. The next day after exposure to pain, these animals either did not enter the dark box at all, or did it after a long latent period. A prolonged latency was also observed 3 days after the pain shock but it predictably decreased after 7 days. It is notable that after 14 days, the duration of the latent period suddenly increased and equaled the one after $24 \mathrm{~h}$. Such a jump in the latent period was observed in other studies as well; however, its mechanism is not yet clear.

The differences in the latency period between the rats transplanted with mutant vs "normalized" cells were highly significant at all time points (except for the point of 7 days): after $24 \mathrm{~h}-\mathrm{p}<0.46$; after $72 \mathrm{~h}-\mathrm{p}<0.004$; after 14 days $-p<0.021$.

Discussion. In addition to changes in the motor functions, the development of parkinsonism is associated with emotional and cognitive impairments [21, 22]. The evolvement of these symptoms is largely due to the fact that along with the degenerative changes in the nigrostriatal brain system, PD also involves mesolimbic and mesocortical dopaminergic systems. Non-motor (e.g., cognitive) manifestations accompany all stages of PD and in some cases may outpace the motor manifestations by $5-10$ years or more [23, 24].

Among the frequent cognitive impairments observed in the early stages of PD, there are slowing of mental processes (bradyphrenia), impaired attention, and memory loss [25]. With the progression of the disease, cognitive dysfunctions are intensified: a further decrease in attention, memory, orientation and thinking can occur, as well as visual and spatial deteriorations. The development of dementia in the late stage of PD significantly complicates the patient's daily activities. In recent years, the importance of non-motor symptoms in early diagnosis and prognosis of PD has been commonly recognized. 
Parkinson's disease is not only a disorder of the dopaminergic system; the neurodegenerative process also involves the acetylcholinergic, noradrenergic and glutamatergic mediator systems. It has been shown that a decrease in brain catecholamines after the conditioned PAR had been developed results in a poor performance, which is seen as a manifestation of retrograde amnesia [26]. The similar effect was found after an injection of 6-OHDA into the substantia nigra of the brain. Along with that, it is known that the passive defensive behavior of animals is due to the mechanisms of fear and thus reflects the state of anxiety [27, 28]. The role of the dopaminergic system in the mechanisms of memory is well documented [29]. The importance of the dopaminergic system for the conditioned reflex of passive avoidance is supported by the results of neuropharmacological inhibition of dopamine D2 receptors [27]. It is known that the avoided/controlled stress can stimulate the release of dopamine in the nucleus accumbens, while the uncontrolled stimuli reduce the release of dopamine [30]. As proposed, the action of dopamine is closely associated with the neural mechanisms of information processing, which in turn determines the strategy of behavior.

The detailed mechanisms of effect of transplants containing "edited" cells on the psychoneurological symptoms in animals with experimental parkinsonism are not yet completely clear. Obviously, the transplantation of neuronal precursors carrying the original mutation decreased the severity of the motor symptoms of PD only. In contrast, the transplantation of the "edited" cells improved both the motor and cognitive deficiencies (preservation of the memory trace). These differences may be associated with a wider influence of the "edited" cells on the dopaminergic structures at various levels of the CNS, and also with their modifying effects on the release of glutamate, gamma-aminobutyric acid and other neurotransmitters in the basal ganglia and their cortical projections. More research is needed to elucidate these putative mechanisms.

Conclusion. The study demonstrates the possibility of correcting motor and cognitive abnormalities in rats with experimental (6-OHDA induced) parkinsonism by repopulating the pool of dopaminergic neurons using neuro-differentiated iPSCs derived from somatic cells (fibroblasts). Thanks to the technology of genome editing, this approach can be extended to benefit patients with hereditary (genetically determined) forms of PD.

Financial Support. The study was supported by the grant from Russian Science Foundation (\#14-1501047-P).

Conflict of Interests. The authors declare no conflict of interests.

\section{References}

1. Illarioshkin S.N. Modern view on etiology of Parkinson's disease. Nevrologicheskiy zhurnal 2015; 20(4): 4-13.
2. Ekstrapiramidnye rasstroystva [Extrapyramidal disorders]. Pod red. Shtoka V.N., Ivanovoy-Smolenskoy I.A., Levina O.S. [Shtok V.N., Ivanova-Smolenskaya I.A., Levin O.S. (editors)]. Moscow: MEDpress-inform; 2002.

3. Wirdefeldt K., Adami H.-O., Cole P., Trichopoulos D., Mandel J. Epidemiology and etiology of Parkinson's disease: a review of the evidence. Eur J Epidemiol 2011; 26(S1): 1-58, https://doi.org/10.1007/s10654-011-9581-6.

4. Airavaara M., Voutilainen M.H., Wang Y., Hoffer B. Neurorestoration. Parkinsonism Relat Disord 2012; 18: S143S146, https://doi.org/10.1016/s1353-8020(11)70045-1.

5. Korecka J.A., Verhaagen J., Hol E.M. Cell-replacement and gene-therapy strategies for Parkinson's and Alzheimer's disease. Regen Med 2007; 2(4): 425-446, https://doi. org/10.2217/17460751.2.4.425.

6. Langston J.W. The promise of stem cells in Parkinson disease. J Clin Invest 2005; 115(1): 23-25, https://doi. org/10.1172/jci24012.

7. Lindvall O. Developing dopaminergic cell therapy for Parkinson's disease - give up or move forward? Mov Disord 2013; 28(3): 268-273, https://doi.org/10.1002/mds.25378.

8. Lindvall O., Kokaia Z., Martinez-Serrano A. Stem cell therapy for human neurodegenerative disorders - how to make it work. Nat Med 2004; 10(7): S42-S50, https://doi. org/10.1038/nm1064.

9. Lebedeva O.S., Lagarkova M.A., Illarioshkin S.N., Khaspekov L.G., Grivennikov I.A. Induced pluripotent stem cells: new possibilities in neurobiology and neurotransplantaion. Annaly klinicheskoy i eksperimental'noy nevrologii 2011; 5(4): 37-45.

10. Gao A., Peng Y., Deng Y., Qing H. Potential therapeutic applications of differentiated induced pluripotent stem cells (iPSCs) in the treatment of neurodegenerative diseases. Neuroscience 2013; 228: 47-59, https://doi.org/10.1016/j. neuroscience.2012.09.076.

11. Hwang D.Y., Kim D.S., Kim D.W. Human ES and iPS cells as cell sources for the treatment of Parkinson's disease: current state and problems. J Cell Biochem 2010; 109(2): 292301, https://doi.org/10.1002/jcb.22411.

12. Nishimura K., Takahashi J. Therapeutic application of stem cell technology toward the treatment of Parkinson's disease. Biol Pharm Bull 2013; 36(2): 171-175, https://doi. org/10.1248/bpb.b12-00929.

13. Takahashi K., Tanabe K., Ohnuki M., Narita M., Ichisaka T., Tomoda K., Yamanaka S. Induction of pluripotent stem cells from adult human fibroblasts by defined factors. Cell 2007; 131(5): 861-872, https://doi.org/10.1016/j.cell.2007.11.019.

14. Lebedeva O.S., Lagar'kova M.A., Kiselev S.L., Mukhina I.V., Vedunova M.V., Usova O.V., Stavrovskaya A.V., Yamshchikova N.G., Fedotova E.Y., Grivennikov I.A., Khaspekov L.G., Illarioshkin S.N. The morphofunctional properties of induced pluripotent stem cells derived from human skin fibroblasts and differentiated to dopaminergic neurons. Neurochemical Journal 2013; 7(3): 207-214, https:// doi.org/10.1134/s1819712413030082.

15. Stavrovskaya A.V., Voronkov D.N., Yamshchikova N.G., Ol'shanskiy A.S., Khudoerkov R.M., Khaspekov L.G., Illarioshkin S.N. Morphochemical evaluation of neurotransplantation outcomes in experimental Parkinsonism. Annaly klinicheskoy i eksperimental'noy nevrologii 2015; 9(2): 28-32.

16. Paxinos G., Watson C. The rat brain in stereotaxic coordinates. Academic Press; 1998. 
17. Vetchinova A.S., Novosadova E.V., Abramycheva N.Yu., Grivennikov I.A., Illarioshkin S.N. PARK8 form of Parkinson's disease: induced pluripotent stem cells-based model and genome editing of LRRK2 mutation. Asimmetriya 2016; 10(4): 90-96.

18. Miroshnichenko E.V., Stavrovskaya A.V., Shugalev N.P., Lenard L., Hartmann G. Emotional state variations in rats during recall of passive avoidance reactions after neurotensin administration into nucleus accumbens of brain. Zhurnal vysshey nervnoy deyatel'nosti im. I.P. Pavlova 2010; 60(6): 704-711.

19. Shugalev N.P., Stavrovskaya A.V., Yamshikova N.G., Olshansky A.S., Kashirina E.A. Neurotensin influence on painful stress afteractions in rats with neurotoxic damages of serotoninergic structures of brain substantia nigra. Zhurnal vysshey nervnoy deyatel'nosti im. I.P. Pavlova 2013; 63(3): 384-394, https://doi.org/10.7868/s004446771303012x.

20. Shugalev N.P., Stavrovskaya A.V., Yamshikova N.G., Olshansky A.S., Miroshnichenko E.V. Reproduction of passive avoidance reactions after neurotensin microinjection into nucleus accumbens of rat brain against the background of reserpine action. Zhurnal vysshey nervnoy deyatel'nosti im. I.P. Pavlova 2012; 62(3): 357-363.

21. Stein M.B., Heuser I.J., Juncos J.L., Uhde T.W. Anxiety disorders in patients with Parkinson's disease. Am $J$ Psychiatry 1990; 147(2): 217-220, https://doi.org/10.1176/ ajp.147.2.217.

22. Uc E.Y., Tippin J., Chou K.L., Erickson B.A., Doerschug K.C., Jimmeh Fletcher D.M. Non-motor symptoms in Parkinson's disease. European Neurological Review 2012; 7(1): 35-40, https://doi.org/10.17925/enr.2012.07.01.35.
23. Vendrova M.I., Golubev V.L., Sadekov R.A., Vein A.M. Motor, cognitive and affective disorders in Parkinson's disease. Zhurnal nevrologii i psikhiatrii imeni S.S. Korsakova 2002; 102(3): 13-17.

24. Chaudhuri K.R., Healy D.G., Schapira A.H. Non-motor symptoms of Parkinson's disease: diagnosis and management. Lancet Neurol 2006; 5(3): 235-245, https://doi.org/10.1016/ s1474-4422(06)70373-8.

25. Yakhno N.N. Cognitive impairment in neurological clinical practice. Nevrologicheskiy zhurnal 2006; 11(S1): 4-12.

26. Alves C.S., Andreatini R., da Cunha C., Tufik S., Vital M.A.B. Phosphatidylserine reverses reserpine-induced amnesia. Eur J Pharmacol 2000; 404(1-2): 161-167, https:// doi.org/10.1016/s0014-2999(00)00607-5.

27. Dubrovina N.I., Popova E.V., Ilyuchenok R.Yu. A compensating-reactivating effect of quinpirole on the extinction of conditional habit and amnesia in mice with alternative behavioral stereotypes. Eksperimental'naya i klinicheskaya farmakologiya 2001; 64(3): 13-16.

28. Molodtsova G.F. Metabolism and receptor binding of serotonin in brain structures during performance of a conditioned passive avoidance response. Neurosci Behav Physiol 2005; 35(7): 685-692, https://doi.org/10.1007/s11055005-0111-4.

29. Goldman-Rakic P.S. The cortical dopamine system: role in memory and cognition. Adv Pharmacol 1997; 42: 707-711, https://doi.org/10.1016/s1054-3589(08)60846-7.

30. Cabib S., Puglisi-Allegra S. Opposite responses of mesolimbic dopamine system to controllable and uncontrollable aversive experiences. J Neurosci 1994; 14(5 Pt 2): 3333-3340. 